\title{
MEDIDAS DE TENSÃO ELÉTRICA PRODUZIDAS POR PLACAS SOLARES CASEIRAS
}

Láira de Cássia Almeida Alves - lairaalmeidaalves@gmail.com

Universidade do Estado do Pará - UEPA/CCNT

Bruno Henrique Batista da Silva - henribatista5852@gmail.com

Universidade do Estado do Pará - UEPA/CCSE

Emmanuelle Tostes Soeiro - e_tostes@ hotmail.com

Universidade do Estado do Pará - UEPA/CCNT

Járlesson Gama Amazonas - jgamazonas@gmail.com

Universidade do Estado do Pará - UEPA/CCSE 


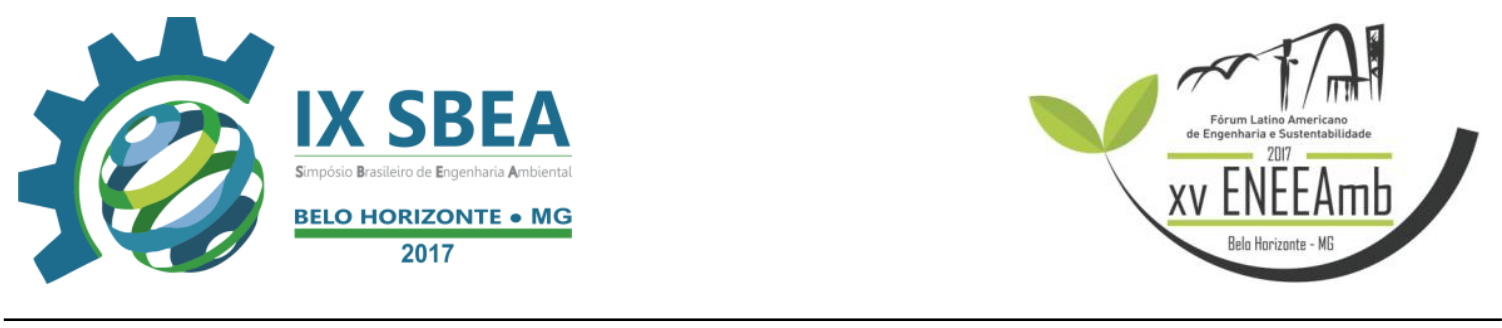

\section{RESUMO}

A energia elétrica no país é produzida em grande por usinas hidrelétricas, apresentando alta dependência do ciclo hidrológico e a inconveniência da construção a longas distâncias dos centros de consumo. O Brasil, por estar localizado nas proximidades da linha do Equador, apresenta elevados níveis de radiação do sol com vasto potencial para a geração descentralizada de energia solar. Em vista disso, de modo alternativo, o presente estudo propõe a construção de painéis solares caseiros com o uso de diferentes tipos de LEDs, investigando os melhores arranjos entres estes de modo a maximizar a tensão elétrica produzida. Selecionou-se LEDs de diferentes tamanhos, tipos e cores, mediu-se a tensão produzida por dispositivo quando exposto ao sol, totalizando mais de 1000 medidas. Os experimentos foram realizados com auxílio de multímetros, ferros de solda, fios condutores e sensores de tensão conectados a plataforma Arduino. Nossos resultados indicam que os dispositivos de radiação infravermelha apresentaram valores de tensão mais constantes, enquanto os LEDs brancos e azuis mostraram medidas muito instáveis, com forte dependência das variações da radiação solar. Percebeu-se uma relação aproximadamente linear entre a quantidade de LEDs em série nos circuitos e a tensão elétrica produzida, e ainda, como padrão, observa-se que os LEDs de menor tamanho produzem maiores valores de tensões elétricas médias. Por fim, apesar dos resultados ainda iniciais, percebe-se uma forma alternativa de produção de energia renovável acessível, contribuindo para a descentralização da matriz energética brasileira.

Palavras-chave: Diodo Emissor de Luz, Placa solar caseira, Medidas de tensão elétrica. 


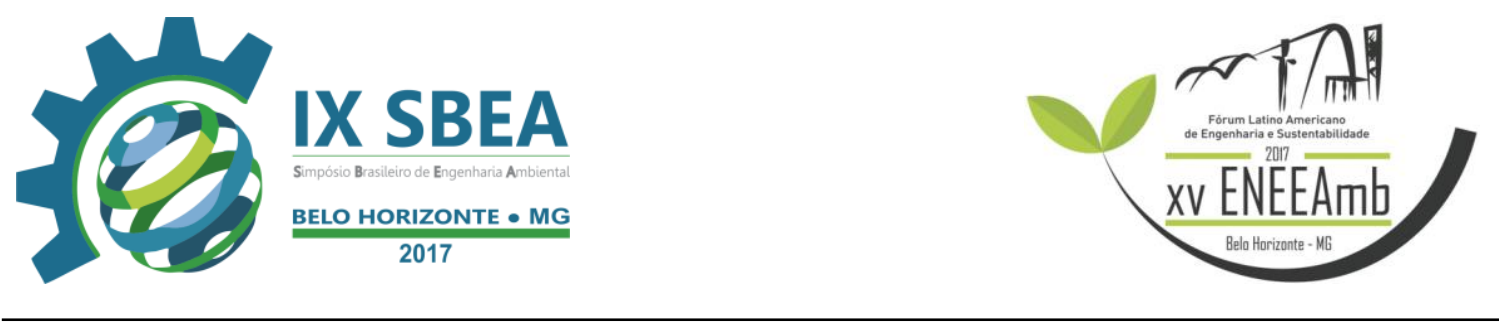

\section{INTRODUÇÃO/OBJETIVO}

A produção de energia brasileira é fortemente dependente de fontes hidráulicas, correspondendo a 61,9\% da matriz energética (EPE, 2016). Em geral, estas usinas apresentam grandes inconvenientes, situam-se a longas distâncias dos centros de consumo e também são altamente dependentes dos ciclos hidrológicos. A distância dos centros urbanos resulta na necessidade de investimentos adicionais em linhas de transmissão para escoamento da produção de eletricidade e a dependência do ciclo hidrológico compromete nossa segurança energética (TOLMASQUIM, 2016). Neste sentido, alguns estudos buscam por novas formas de produção descentralizada de energia como a microgeração hidráulica (LOPES et al., 2016) ou a partir de células solares caseiras feitas com LEDs - diodos emissores de Luz (OKAMOTO, 2010). Sabese ainda que o Brasil está situado em uma região com grande incidência vertical de raios solares, o que favorece elevados índices de irradiação em quase todo o território nacional, apresentando pouca variação na incidência solar ao longo do ano devido à proximidade da linha do equador. Dessa forma, mesmo no inverno pode haver bons níveis de irradiação, conferindo ao país algumas vantagens para o aproveitamento energético do recurso solar (EPE, 2016). O cenário é tão promissor que além dos 44 empreendimentos de fonte fotovoltaica em funcionamento no país, outros 37 já estão em construção e ainda, existem ao menos 74 novos projetos para construção de novas usinas solares (ANEEL, 2017).

Alternativamente, investiga-se neste trabalho a produção de energia fotovoltaica de forma inovadora e descentralizada utilizando diodos emissores de luz (LEDS). Estes dispositivos foram fabricados para transformar energia elétrica em luz, mas apresentam inúmeras aplicações em diversos campos da ciência, sendo uma delas, a geração de energia elétrica (OKAMOTO, 2010). Por serem constituídos pela junção de material semicondutor tipo p e semicondutor tipo n (ALVES, 2008) podem ser usados na confecção de módulos solares. Assim, objetiva-se estudar o uso de LEDS de diferentes cores, tamanhos e dispostos em diversas configurações para construção de painéis fotovoltaicos que maximizem a tensão elétrica gerada, contribuindo para o desenvolvimento de fontes alternativas de energia. 


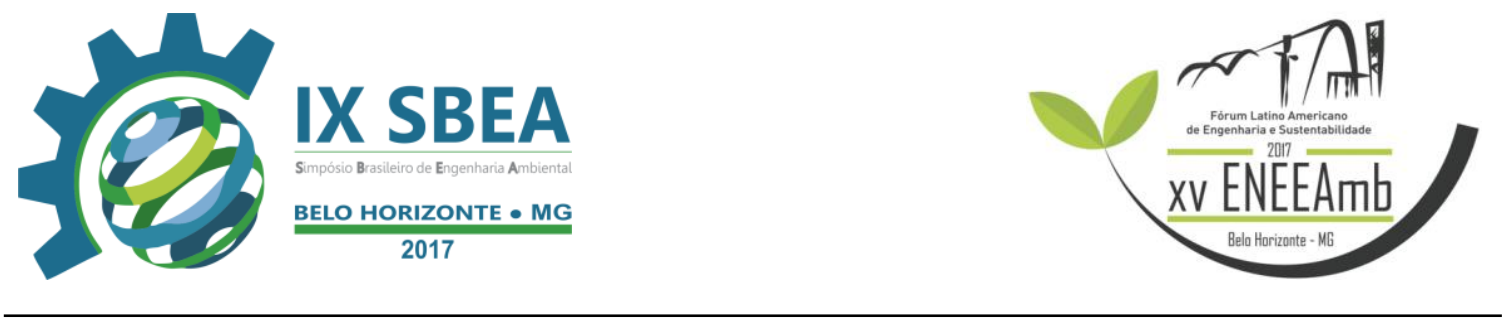

\section{METODOLOGIA}

Primeiramente, realizou-se breve inspeção do funcionamento e da produção de tensão elétrica por LEDs individuais. Em seguida, construíram-se circuitos variando a cor (branco, azul e infravermelho), o tamanho (3 $\mathrm{mm}$ e $5 \mathrm{~mm}$ ), a quantidade $(6,12$ e 24 unidades) e a disposição (série, paralelo, misto) dos LEDs. As medidas foram realizadas com multímetros e quando possível com auxílio de sensores de tensão acoplados a plataforma Arduino UNO. Os materiais necessários para a construção das placas foram LEDs, placas de circuito, ferros de solda, solda, alicate de corte, fios de ligação, jacarezinhos e estiletes conforme mostra a Figura 1. O LED de cor branca foi selecionado por representar a mistura de todas as cores; os de cor azul representam o extremo do espectro visível de altas energias, enquanto os LEDs infravermelhos foram escolhidos por representar uma região de baixas energias, fora do intervalo do espectro visível.

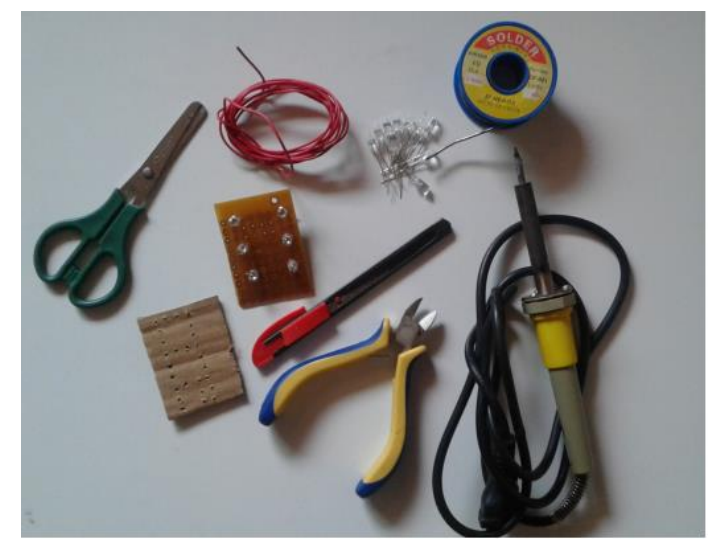

Figura 1. Materiais necessários para as medidas em 1 (um) LED, placas de 6 (seis) e placas de 12 (doze) e placas de 24 (vinte e quatro) LEDs: placa de circuito, solda, ferro de solda, alicate de corte, fios de ligação e estilete. As medidas elétricas foram realizadas com auxílio de multímetros e sensores de tensão via plataforma Arduino.

\section{Montagem das placas com 6 (seis) LEDs}

Cortou-se uma placa de circuito em quatro partes, em cada uma delas, encaixaram-se 6 (seis) LEDs igualmente espaçados, dispostos em três linhas e duas colunas conforme mostra a Figura 2. No total foram construídos 6 (seis) circuitos com 6 


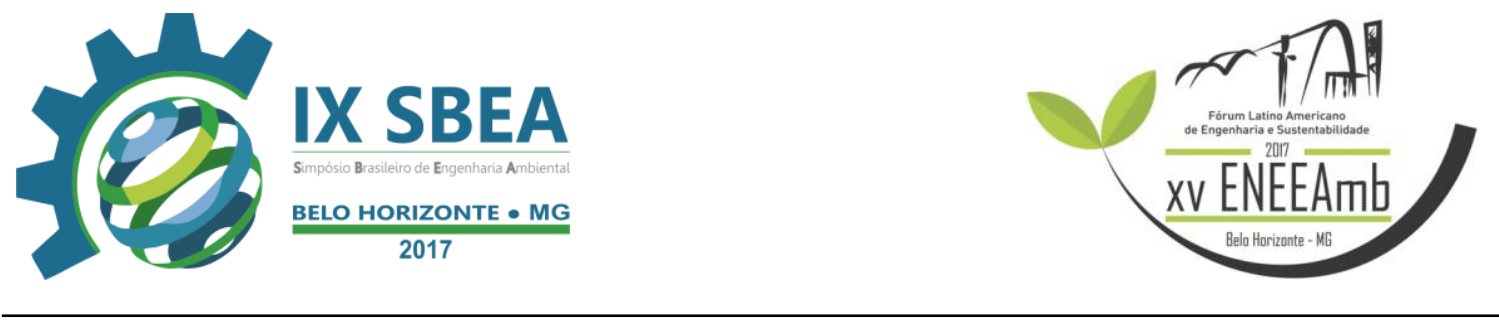

(seis) LEDs de 3mm e 5mm, nas cores branco, azul e infravermelho. Em cada placa, dobraram-se os polos positivos dos LEDs para dentro do circuito e os polos negativos para a lateral deste. Assim, na parte interna, no espaço entre as duas colunas, formaramse três ligações de polos positivos, que foram unidas por fio condutor vermelho, e nas bordas se formaram ligações de polos negativos, unidas por fio condutor preto. $\mathrm{Na}$ base das placas, foi deixado um pedaço de cada fio descascado para se conectar o multímetro.

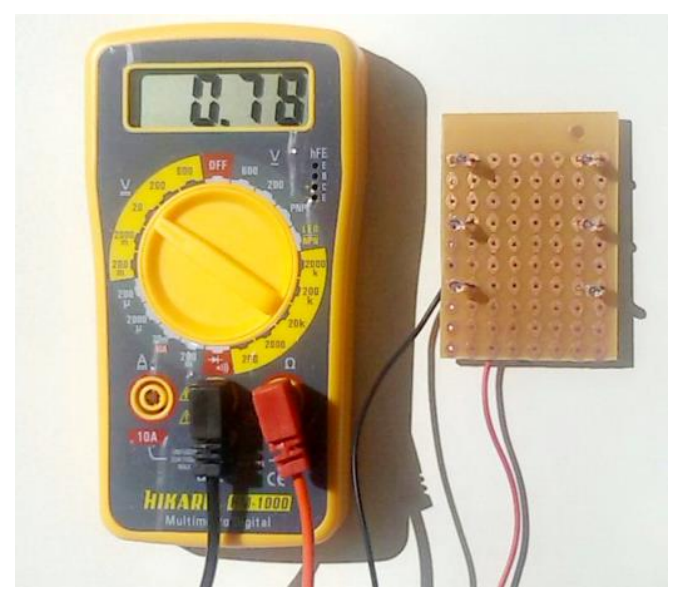

Figura 2. Circuito com 6 (seis) LEDs infravermelhos de 3mm. As medidas de tensão produzida foram realizadas através de multímetros.

\section{Montagem das placas com 12 (doze) LEDs}

Cortou-se uma placa de fenolite em duas partes, em cada uma delas, encaixaram-se 12 (doze) LEDs igualmente espaçados, dispostos em três colunas e quatro linhas, conforme mostra a Figura 3. Em cada coluna, colocaram-se dois LEDS em série unidos pelo polo positivo livre de cada par, enquanto que seus polos negativos foram unidos com os da linha adjacente. Assim, na parte interna do circuito, formaramse além do polo negativo e positivo, ligações mistas. O polo negativo foi interconectado pelo fio preto e o positivo, interconectado pelo fio vermelho. $\mathrm{Na}$ base das placas, foi deixado um pedaço de cada fio descascado para se conectar o multímetro. No total, montaram-se quatro placas de 12 (doze) LEDS, de tamanhos $3 \mathrm{~mm}$ e $5 \mathrm{~mm}$, dos tipos azul e infravermelho. 

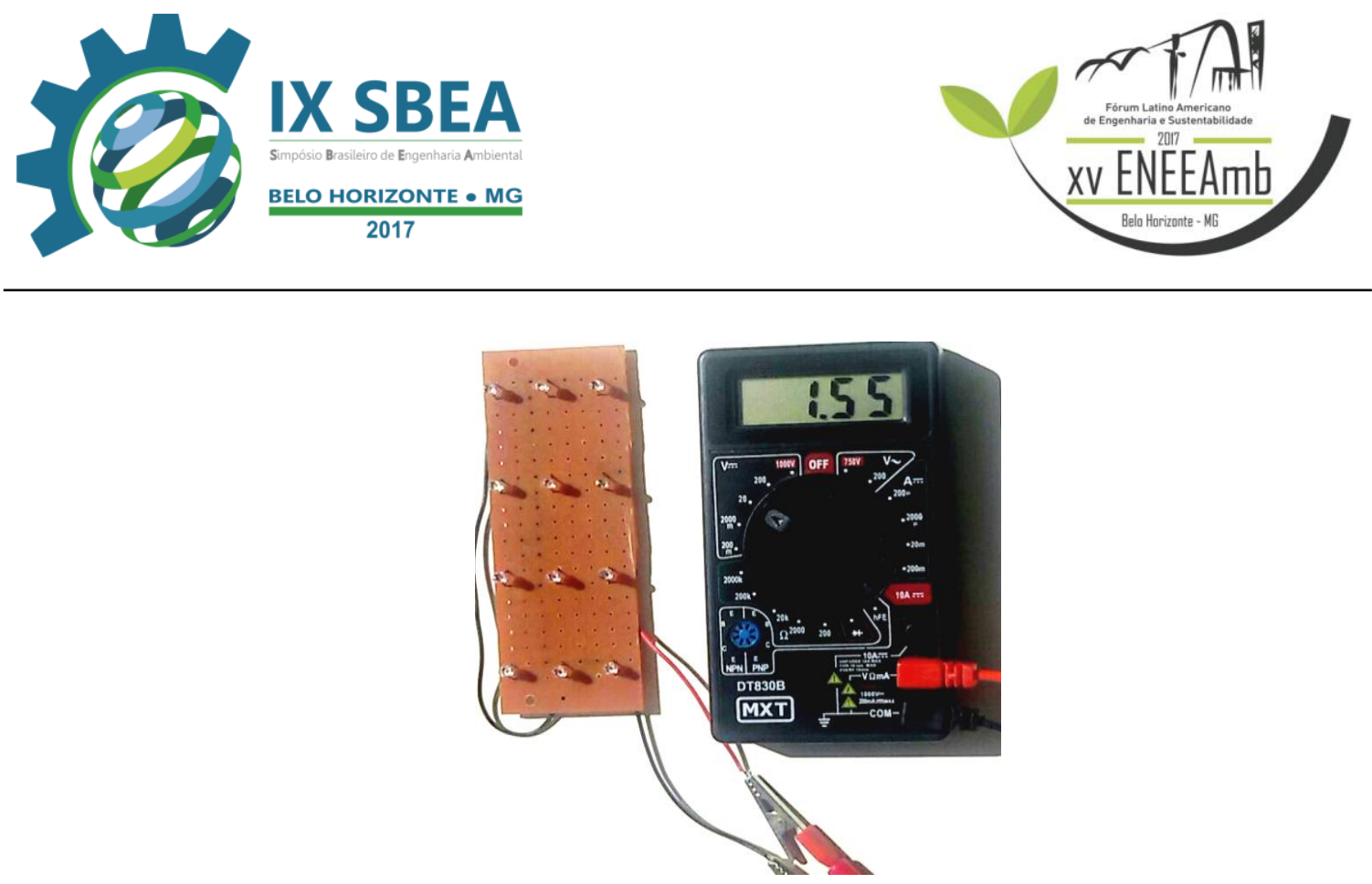

Figura 3. Circuito com 12 (doze) LEDs infravermelhos de 3mm. As medidas de tensão produzida foram realizadas através de multímetros.

\section{Montagem da placa de 24 (vinte e quatro) LEDs}

Usaram-se placas de fenolite para conectar 24 (vinte e quatro) LEDs infravermelhos de $3 \mathrm{~mm}$ e $5 \mathrm{~mm}$, dispostos em três colunas e oito linhas, conforme mostra a Figura 4. Em cada coluna foram conectados quatro LEDs em série unidos pelo polo positivo livre de cada par, enquanto que seus polos negativos foram unidos com os da linha adjacente. Na parte interna do circuito, formaram-se além do polo negativo e positivo, ligações mistas. O polo negativo foi interconectado pelo fio preto e o positivo, interconectado pelo fio vermelho. $\mathrm{Na}$ base das placas, foi deixado um pedaço de fio desencapado para realizar as observações. As medidas das voltagens foram realizadas com auxílio de multímetros e através de sensores de tensão conectados a plataforma Arduíno UNO. 

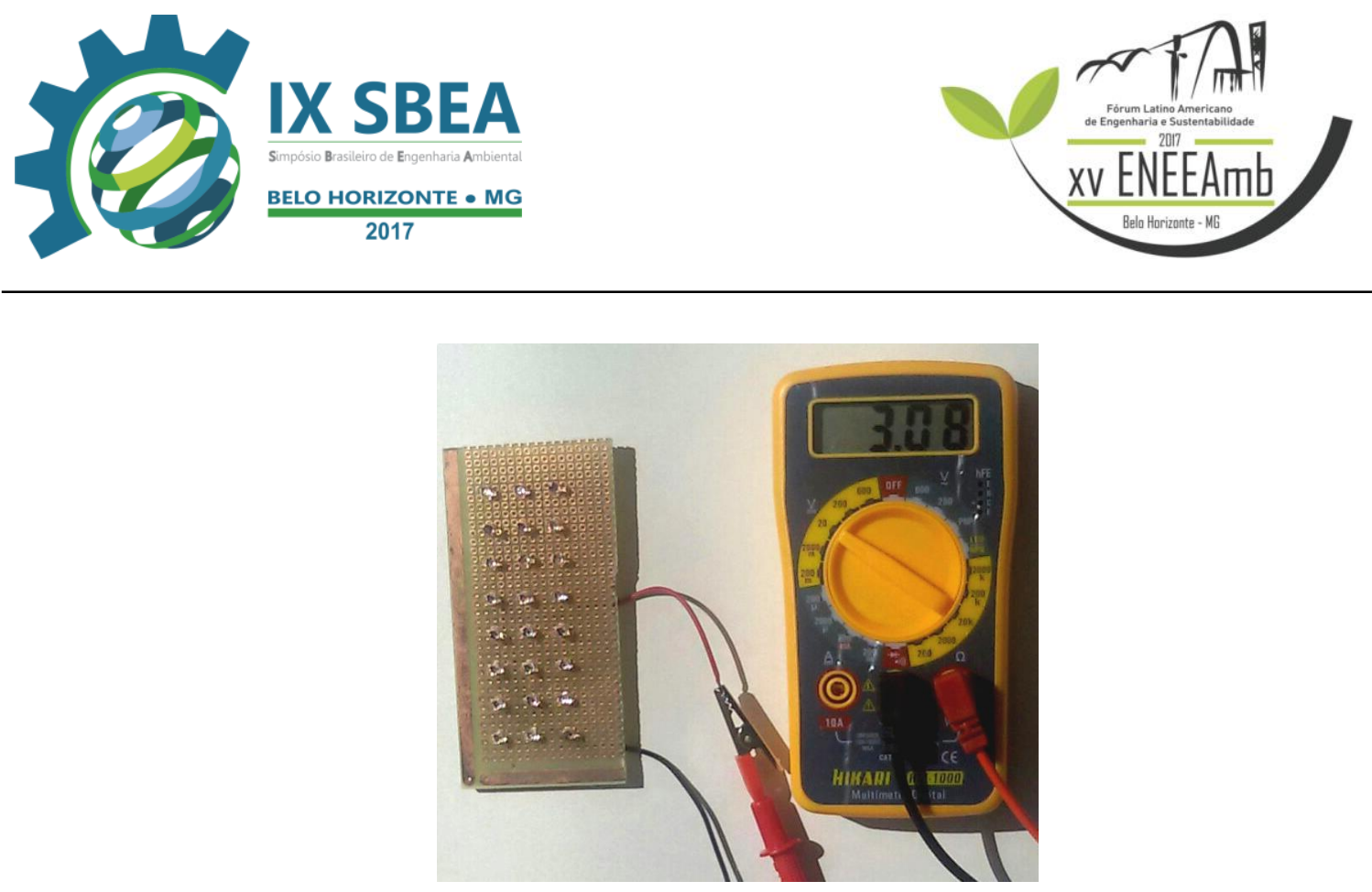

Figura 4. Circuito com 24 (vinte e quatro) LEDs infravermelhos de $3 \mathrm{~mm}$. As medidas de tensão produzida foram realizadas através de multímetros e com auxílio de sensores de tensão acoplados a plataforma Arduino.

\section{RESULTADOS E DISCUSSÃO}

Tensões médias geradas por LEDs individuais e por placas de 6 (seis) LEDs

O monitoramento dos diodos foi feito individualmente, durante cinco dias consecutivos, realizando 10 (dez) medidas por dispositivo entre $10 \mathrm{~h}$ e $11 \mathrm{~h}$ da manhã e 10 (dez) realizadas entre $11 \mathrm{~h}$ e $12 \mathrm{~h}$, totalizando 20 (vinte) medições por dia, totalizando 400 valores. A partir destes, calculou-se o valor médio de tensão produzida por dia e por LED, no decorrer de cinco dias de observações, conforme ilustra a Figura 5(a).

No primeiro dia, as médias dos valores de tensão produzidos pelo LED de $5 \mathrm{~mm}$ infravermelho (IRE) foram de $0,74 \mathrm{~V}$, a do LED azul, foi de $0,07 \mathrm{~V}$ e a do LED branco, foi de $0,05 \mathrm{~V}$. As tensões observadas para os LEDs de $3 \mathrm{~mm}$ são ligeiramente maiores. Resultados mais discrepantes ocorrem para os LEDs azuis no quarto dia de observações, em que o LED de $5 \mathrm{~mm}$ apresenta tensão média praticamente nula, enquanto do dispositivo de $3 \mathrm{~mm}$ gera tensão média de 1,2 V. 


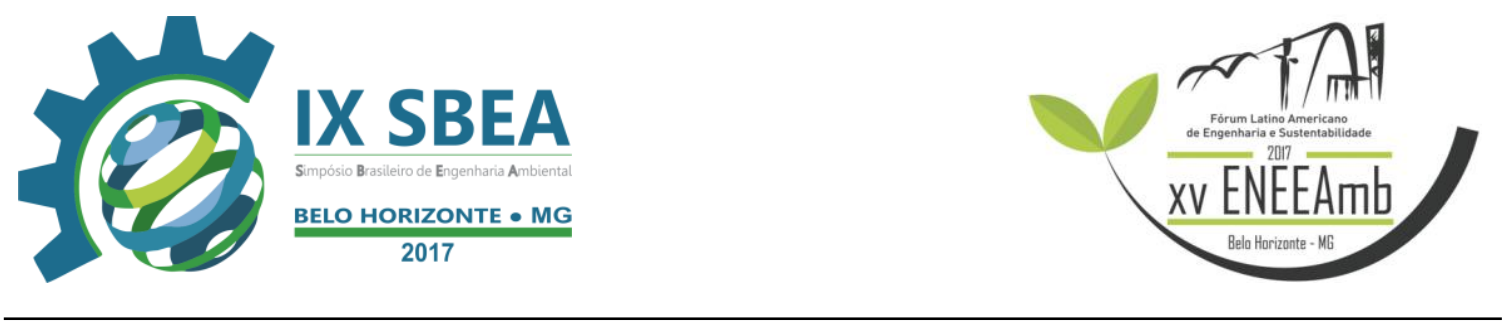

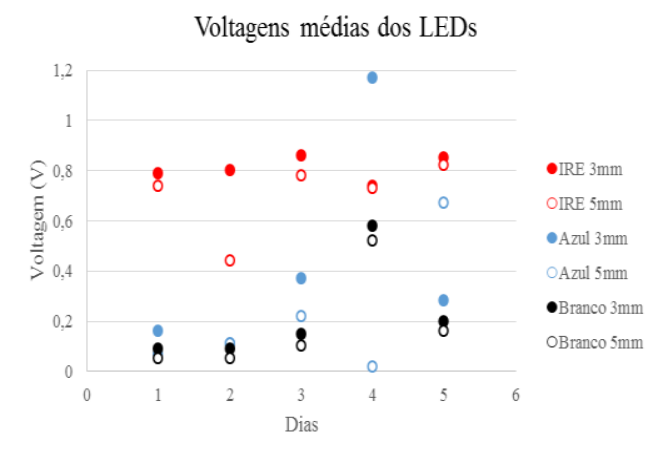

(a)

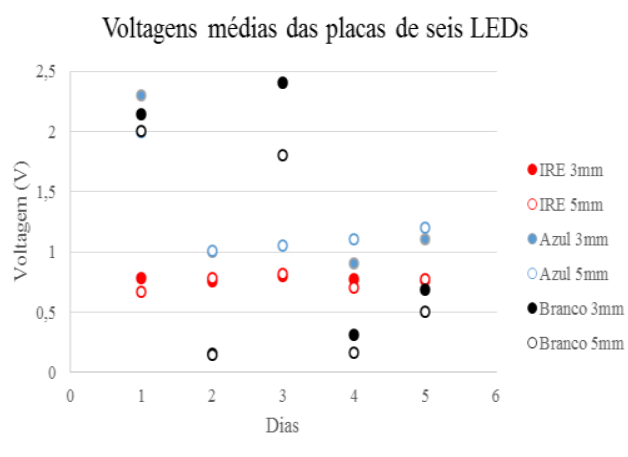

(b)

Figura 5. Tensões médias produzidas por LEDs de $3 \mathrm{~mm}$ e $5 \mathrm{~mm}$, infravermelhos, azuis e brancos. Em (a) para LEDs individuais e em (b) para placas cm 6 (seis) LEDs em paralelo. As medidas foram realizadas com auxílio de multímetros.

Similarmente, após construção e testes de funcionamento, as placas de 6 (seis) LEDs foram expostas a radiação solar e sua tensões produzidas foram medidas com ajuda de multímetros. Para cada placa foram realizadas 100 (cem) medidas, totalizando 400 dados, cujos valores médios por dia e por tipo de LED estão mostrados na Figura 5(b), considerando os LEDs brancos, azuis, IREs de $3 \mathrm{~mm}$ e $5 \mathrm{~mm}$.

Como observado, a partir das medidas em diodos individuais e em placas de 6 (seis) LEDs indicados na Figura 5(a) e Figura 5(b), os dispositivos infravermelhos (IRE) apresentaram tensões bastante estáveis, enquanto os LEDs branco e azul produziram tensões fortemente dependentes da radiação solar, fornecendo para um mesmo dia as tensões mais baixas e mais altas. Verifica-se também que as tensões produzidas pelos dispositivos de $3 \mathrm{~mm}$ são ligeiramente maiores que aquelas observadas para LEDs de $5 \mathrm{~mm}$.

\section{Tensões médias geradas por placas de 12 (doze) e 24 (vinte e quatro) LEDs}

Em vista dos resultados anteriores para tensões produzidas por 1 LED e pelas placas de 6 LEDs, decidiu-se confeccionar placas de 12 (doze) LEDs somente para os dispositivos IREs (resultados estáveis, baixa energia) e azuis (instáveis, altas energias). Dessa forma, construíram-se duas placas idênticas de 12 (doze) LEDs de $3 \mathrm{~mm}$ e $5 \mathrm{~mm}$, azuis e IREs. 


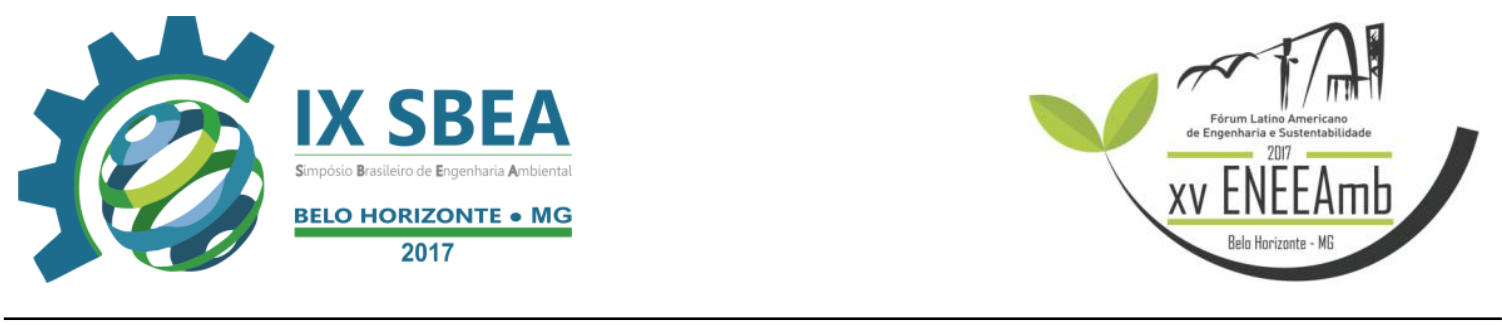

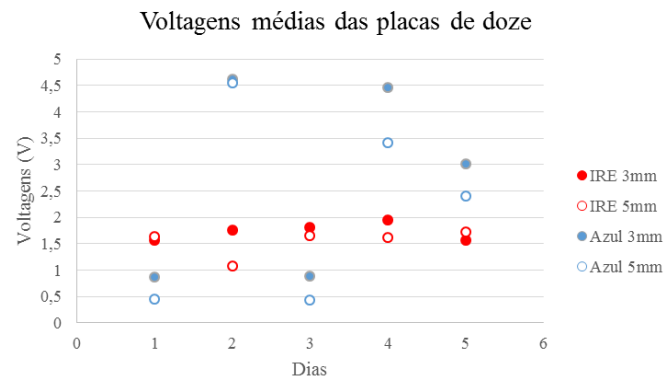

(a)

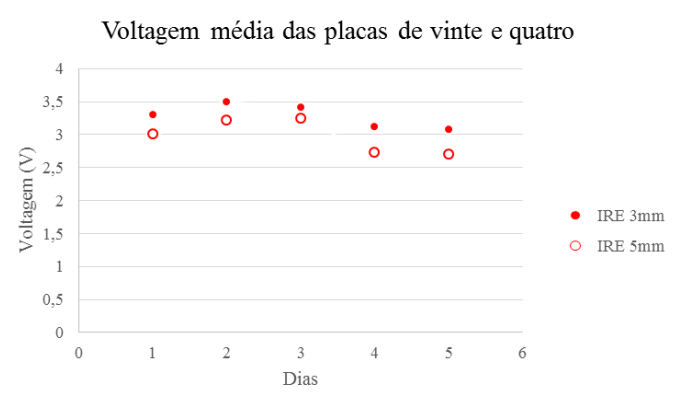

(b)

Figura 5. Tensões médias produzidas por LEDs de $3 \mathrm{~mm}$ e $5 \mathrm{~mm}$. Em (a) para 12 LEDs infravermelhos e azuis, e em (b) para placas com 24 LEDs infravermelhos. As medidas foram realizadas com auxílio de multímetros.

O monitoramento das placas de 12 (doze) LEDs foi realizado ao longo de cinco dias consecutivos. Para cada placa foram realizadas 40 (quarenta) medições por dia, 20 (vinte) delas realizadas entre $10 \mathrm{~h}$ e $11 \mathrm{~h}$ da manhã e 20 (vinte) realizadas entre $11 \mathrm{~h}$ e 12h. Ao todo, para cada placa, obteve-se 200 (duzentos) valores resultando em um total de 800 (oitocentas) medidas. A Figura 5(a) ilustra as voltagens geradas por cada placa de 12 LEDs azuis e dispositivos IREs a cada dia. O comportamento anteriormente observado permanece, com ênfase na estabilidade dos dispositivos infravermelhos (IREs) e grande variação da tensão produzida pelos LEDs azuis.

Confeccionou-se ainda, placas de 24 (vinte e quatro) LEDs de $3 \mathrm{~mm}$ e $5 \mathrm{~mm}$ apenas para os dispositivos infravermelhos. Como mencionado anteriormente, as medidas foram realizadas ao longo de cinco dias, e os valores médios de tensão produzida estão dispostos na Figura 5(b) e foram obtidos através de multímetros. Os valores produzidos por LEDs de $3 \mathrm{~mm}$ são ligeiramente maiores que os correspondentes de $5 \mathrm{~mm}$, ainda, vale citar uma relação aproximadamente linear envolvendo o número de LEDs em serie nos circuitos com a tensão produzida, o que explica os valores de tensão observados nas Figuras 5(a) (para 12 LEDs IREs) em torno de 1,5 V enquanto aqueles da Figura 5(b) (para 24 LEDs IREs) produzem tensões que oscilam em torno de $3,0 \mathrm{~V}$. 


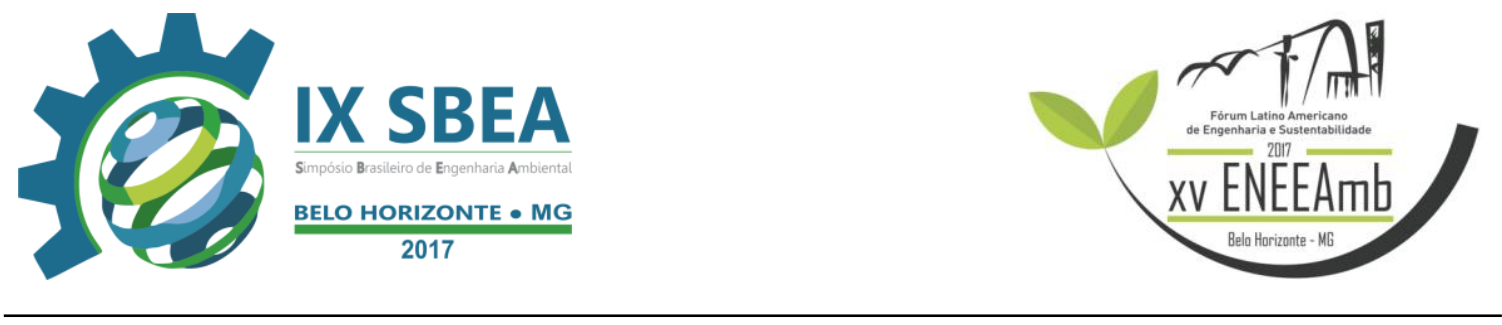

\section{Monitoramento via plataforma Arduino}

As placas de 24 LEDs infravermelhos de $3 \mathrm{~mm}$ e $5 \mathrm{~mm}$ foram novamente expostas a radiação solar, e as medidas de voltagem foram realizadas usando sensores de tensão conectados a um microcontrolador Arduino UNO. A leitura dos valores de tensão foi programada para ser realizada em intervalos de 3 (três) segundos, gerando 20 (vinte) dados a cada minuto. Além disso, os valores lidos pelo sensor de tensão foram calibrados considerando para isto as medidas realizadas com os multímetros. Os resultados de tensão gerada para placas de 24 LEDs infravermelhos, de $3 \mathrm{~mm}$ e $5 \mathrm{~mm}$, estão dispostos na Figura 6. Enfatiza-se inicialmente que os valores observados via plataforma Arduino dispostos na Figura 6 concordam plenamente com aqueles medidos com auxílio de multímetros apresentados na Figura 5(b). Como observado anteriormente, existe uma estabilidade nas tensões produzidas, as quedas de tensão são devidas as inesperadas mudanças climáticas com baixa radiação solar, e ainda, percebese a partir da Figura 6 que os LEDs infravermelhos de $3 \mathrm{~mm}$ novamente produziram tensões acima (pouco) daqueles gerados pelos LEDs de $5 \mathrm{~mm}$.

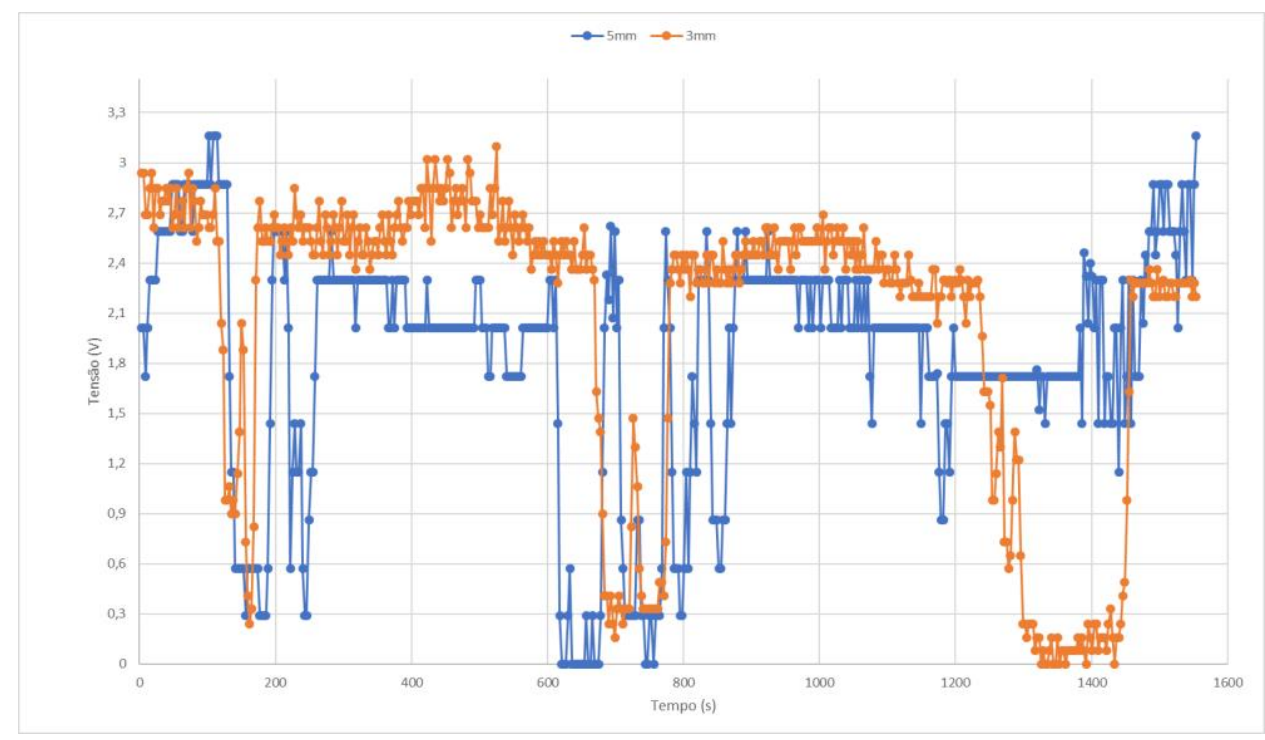

Figura 6. Tensões produzidas por placas de 24 LEDs infravermelhos de $3 \mathrm{~mm}$ e $5 \mathrm{~mm}$ monitorados via plataforma Arduino. 


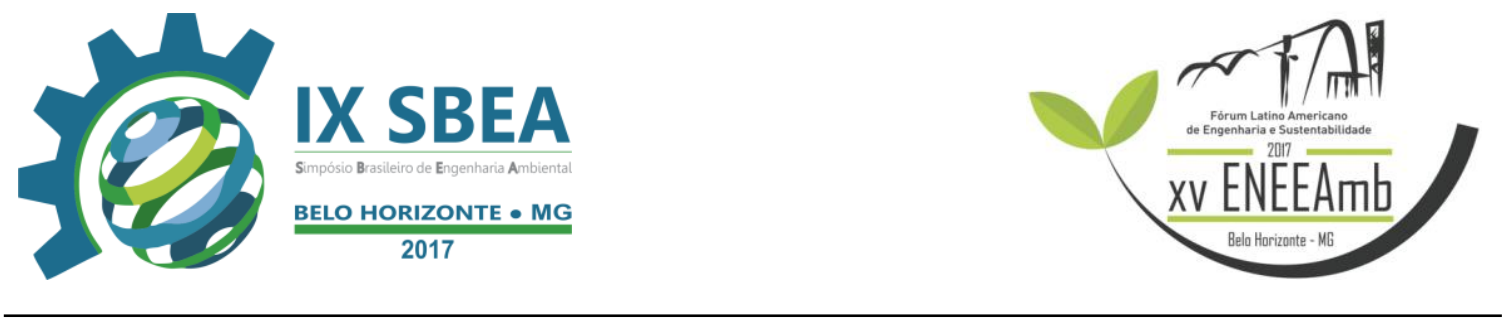

\section{CONCLUSÕES/RECOMENDAÇÕES}

Os valores de tensão observados nos LEDs individuais estão em acordo com aqueles medidos nas placas de 6 LEDs, pois nestas placas os dispositivos estão todos em paralelo. As medidas de voltagem geradas nas placas de 12 LEDs correspondem a praticamente o dobro daqueles observados nas placas de 6 LEDS, e da mesma forma, as tensões medidas pelas placas de 24 LEDs geram tensões médias proporcionais, apresentando uma relação linear entre o número de LEDs por placa e tensão média produzida. De modo geral, as tensões produzidas pelos LEDS brancos e azuis apresentam fortes oscilações mesmo com pequenas mudanças climáticas, enquanto os LEDs infravermelhos apresentam alta estabilidade, e ainda, como padrão, observou-se que os LEDs menores $(3 \mathrm{~mm})$ produzem voltagens ligeiramente maiores. A partir destes resultados, percebe-se uma forma alternativa de produção de energia renovável que merece ser mais explorada, contribuindo para a descentralização da matriz energética brasileira e com possiblidades de geração de energia elétrica mesmo em regiões remotas.

\section{REFERÊNCIAS BIBLIOGRÁFICAS}

AGÊNCIA NACIONAL DE ENERGIA ELÉTRICA (ANEEL). Banco de Informações de Geração.

Disponível

em:

http://www2.aneel.gov.br/aplicacoes/capacidadebrasil/capacidadebrasil.cfm. Acesso em: 31 mar. 2017.

ALVES, E. G.; SILVA, A. F.; Usando um LED como fonte de energia. Física na Escola, Belo Horizonte, v.9, n.1, p. 26-28, 2008.

EMPRESA DE PESQUISA ENERGÉTICA (EPE). Anuário Estatístico de Energia Elétrica 2016. Disponível em: http://www.epe.gov.br. Acesso em: 31 mar. 2017.

LOPES, K.; FONSECA, V. S.; PARENTE, Y. Y.; SOUZA, W. C. de; AMAZONAS, J. G. Observação de vazão hidráulica residencial como potencial gerador de eletricidade monitorado via plataforma ARDUINO. In: Anais do XIV Encontro Nacional de Estudantes de Engenharia Ambiental [= Blucher Engineering Proceedings v.3 n.2]. São Paulo:

Blucher, 2016. p. 712-719.

ISSN 2357-7592, DOI 10.5151/engpro-eneeamb2016-er-003-5016.

OKAMOTO, K.; Intelligent Non-Conventional Applications of LEDs. Transactions of Japan Institute of Electronics Packaging. v. 3, n.1, p.9-28, 2010.

TOLMASQUIM, M. T. Energia Renovável: Hidráulica, Biomassa, Eólica, Solar e Oceânica. Interciência, 2003. 129 p. 